\title{
STUDYING NEW VENTURE IDEAS USING AN ONLINE FUNDING PLATFORM
}

\author{
Manjiri Kunte* and Triyuth Promsiri \\ Stamford International University, Asoke Campus Learning Center, Exchange Tower, \\ $G \&$ LG Floor, 388 Sukhumvit, Klongtoey, Bangkok 10110, Thailand \\ *Corresponding author: manjiri.kunte@stamford.edu
}

Published online: 27 June 2019

To cite this article: Kunte, M. and Promsiri, T. (2019). Studying new venture ideas using an online funding platform. Asian Academy of Management Journal, 24(1), 111-128. https://doi.org/10.21315/aamj2019.24.1.5

To link to this article: https://doi.org/10.21315/aamj2019.24.1.5

\begin{abstract}
Venture ideas in the entrepreneurship process have been studied as a micro-level construct and have been defined in multiple ways in literature. However, previous reviews indicate a lack of studies on the qualities of opportunities or venture ideas and of empirical evidence regarding their effects on entrepreneurial process outcomes. To address this issue, the current study attempts to validate five characteristics of the new venture ideas construct (Davidsson, 2015) towards the outcome variable of the decision to invest or not. The study utilises 80 new venture ideas (projects) from the online funding website. A group of five entrepreneurs rated these ideas independently on novelty, appropriability, diffusability, scalability, and scope, using a 5-point Likert scale ranging from " $1=$ not at all" to "5 = extremely". A comparison of the results from regression analysis by the judges and the backers on the funding platform suggested that the characteristic of appropriability was the most important factor in determining the final investment decision. Empirical support for the definition and characteristics of new venture ideas and the validity of appropriability as a significant indicator of the investment decision are the main contributions of this study. The findings of this study will be helpful to both entrepreneurs and investors alike in the future.
\end{abstract}

Keywords: entrepreneurial opportunities, new venture ideas, funding platform, investment decision, entrepreneurs

(C) Asian Academy of Management and Penerbit Universiti Sains Malaysia, 2019. This work is licensed under the terms of the Creative Commons Attribution (CC BY) (http://creativecommons. org/licenses/by/4.0/). 


\section{INTRODUCTION}

As Alvarez and Barney (2007a) metaphorically put it, the entrepreneurial process is more comparable to building or creating mountains rather than climbing them. In this creation process, the identification and selection of the right opportunities serve as the starting points (Shane \& Venkataraman, 2000; Stevenson, Roberts, \& Grousbeck, 1989). More specifically, the entrepreneurial success should be determined by the qualities of the opportunities that they pursue (Davidsson, Recker, \& von Briel, 2018). Until recently, the conceptualisation of entrepreneurial opportunities (with respect to the entrepreneurial process) has been done in various ways (Davidsson, 2015; Short, Ketchen, Shook, \& Ireland, 2010; Vogel, 2017). Entrepreneurial opportunities are connected with factors under the actor-entrepreneur fit (Shane \& Venkataraman, 2000), or expressed as a discovery (Alvarez \& Barney, 2013), with knowledge and memory base (Baron, 2006). Shane (2012) defines opportunities as situations in which the actor (entrepreneur) combines resources in a way that generates profit. Shane details further that entrepreneurs create and enact plans to generate a profit in response to their own beliefs about opportunities. However, this favourability-based hypothesis does not assist in drawing a clearer definition of the term. Overall, these studies indicate that opportunities were identified as the outcomes of a process or as preexisting external conditions (Davidsson 2015; Eckhardt \& Shane, 2010, 2013; Shane, 2012). Ramoglou and Tsang (2016) define opportunity as "the propensity of market demand to be actualized into profits through the introduction of novel products or services" (p. 411). Notably, not many of these studies explore opportunities as an independent variable. In addition, none of these prior conceptualisations categorise the characteristics of opportunities as independent of the entrepreneur's perspective (Davidson \& Tonelli, 2013), and thus the concept of opportunity seems "elusive" (Davidsson, 2015, p. 675).

Apparently, only a few studies (e.g., Alvarez \& Barney, 2007a; Dahlqvist \& Wiklund, 2012; Parker, 2011; Vogel, 2017) have depicted the use of certain aspects of opportunity, such as novelty, economic value, relevance or desirability, risk or uncertainty, specificity, and workability, as characteristics that define the entrepreneurial action and outcome. Ramoglou and Tsang (2016) suggest profitability and novelty as defining characteristics. Williams and Wood (2015) consider novelty and resource efficiency to appraise opportunities. However, any operationalisation of these characteristics is unavailable (Davidsson, 2015). Shane and Venkataraman (2000) put forth a significantly different perspective by suggesting how the characteristics of opportunities directly and indirectly gave shape to the entrepreneurial processes. The study proposed that the characteristics of individuals (as actors), and the characteristics of opportunities (as non-actors) together 
explain the effectiveness of the identification, initiation, progress, and success of the entrepreneurial process. However, it is notable that the conceptualisation of opportunity in Shane and Venkataraman's view was synonymous with success. This led to two outcomes: first, any failure in the entrepreneurial process could not be attributed to the non-actor component in the nexus framework; and second, any operationalisation of an opportunity was not possible because it was beyond the actor's control. Vogel (2017) consolidated the construct measurement and proposed that there are many characteristics of opportunities spread across various stages of idea generation, development, and exploration. At the initial stage, ideas might vary in terms of scope (quantity), complexity (quality), and completeness (variety). At the development and exploitation stage, ideas might differ in novelty, desirability, and feasibility.

Altogether, the concept of entrepreneurial opportunity portrayed in the literature prevents not only any operationalisation of an opportunity as an independent variable, but also the exploration of the effects it has on the entrepreneurial process. With the exception of Vogel (2017), none of the previous conceptualisations of opportunity fully support the understanding of the specific characteristics of opportunities in the entrepreneurial process (Alvarez \& Barney, 2013; Davidsson, 2015; Dimov, 2011). Hence, it can be inferred that the identification and the operationalisation of the characteristics of the opportunity construct is a research gap meriting attention (Davidsson \& Tonelli, 2013).

\section{LITERATURE REVIEW}

\section{The Three-Legged Approach}

Developing the non-actor component of the individual-opportunity nexus framework by Shane and Venkataraman (2000), the studies by Davidsson and Tonelli (2013) and Davidsson (2015) proposed three constructs to replace the opportunity construct. The three constructs are:

1. External enablers. This first construct acknowledges environmental support in the form of external enablers, which denote external circumstances and act as a support in the possible venture development attempts (to be) pursued by the entrepreneurs. In addition, the enablers are temporary and are dependent on the specific space, time, and application area. External enablers are measured at an aggregate level because the term "enablers" refers to more than one individual and more than one activity. 
2. New venture ideas (NVI). This second construct refers to the cognitive economic activity which results from the combination of products/ services, the markets/users, and the means of bringing them into existence. When linked with the first construct, it can be inferred that NVIs are an entrepreneur's interpretation of identifiable external enablers. The level of measurement for the NVI is one venture where the characteristics of NVIs can be identified and separated distinctly from the entrepreneur him/ herself. In addition, the NVIs can be assessed differently by individuals depending on their characteristics and effect on the outcomes.

3. Opportunity confidence. The third construct denotes the opportunity evaluation carried out by the entrepreneur (a comparison of the previous two) and the result in the form of confidence, ranging from negative to positive, in order to implement and complete his/her entrepreneurial process. This last component in the three-legged construct denotes the subjective evaluation carried out by the entrepreneur him/herself, and this can vary across different entrepreneurs for the same set of external enablers and NVIs. The level of measurement for the opportunity confidence is the evaluator and the evaluated.

Davidsson (2015) suggested that the three constructs detailed above would assist in the establishment of a separate opportunity construct, which would be independent of the favourability bias and thus able to explain both the success and failure of an entrepreneurial activity. Secondly, the three-legged approach will bring a certain level of certainty to the otherwise unknown and uncertain nature of opportunities as pointed out by Eckhardt and Shane $(2010,2013)$.

\section{NVI Construct}

Out of the three aforementioned constructs, the NVI construct is the only microlevel companion of the entrepreneur during the entrepreneurial process, and thus is the most workable out of the three constructs (Davidsson \& Tonelli, 2013). The NVI construct is defined as a set of evolving and dynamic outlines of a future venture, which guide the venture creation process. NVIs reflect cognitive thinking on the part of an actor and is a venture level construct as previously specified. A comparison of this new construct with the previous concepts of opportunity suggests a major difference whereby NVIs do not reflect any element of favourability or positivity of the opportunity. Hence, the construct is also defined as a value neutral, subjective perception, which guides entrepreneurial action. The operationalisation of the NVI construct assists in the identification and assessment 
of the characteristics of opportunities towards outcomes. Davidsson and Tonelli (2013) and Davidsson (2015) described this as a much less contentious and a much more coherent and workable construct which can be used by entrepreneurs and investors alike to support their decisions during the entrepreneurial process (Davidsson \& Tonelli, 2013).

The other advantages of employing this conceptualisation of entrepreneurial opportunity are the identification of the characteristics of the NVI, an effective operationalisation, and the development and testing of theoretical support towards the success and failure of entrepreneurial action and investment decisions. In addition to these foundational issues, the empirical support for the NVI characteristics will be helpful in imparting a sense of confidence in the nascent entrepreneurs looking to embark upon their first entrepreneurial attempts (Davidsson \& Tonelli, 2013).

\section{The Characteristics of NVI}

As Vogel (2017) suggests, "the entrepreneurial process does not take place in isolation, but is embedded in the social and environmental context of the entrepreneur" (p. 6). Newness and smallness are the two distinguishing features of a new venture, and these can be either liabilities or assets (Shepherd, 1999; Stampfl, Prügl, \& Osterloh, 2013). Qualities such as "imperfect imitability" (Oviatt $\&$ McDougall, 1993) or the attributes of the environment, individual, process, and organisation (Gartner, 1985) constitute the characteristics of a new venture. Drawing from strategy, innovation, and entrepreneurship research, Davidsson and Tonelli (2013) proposed the following as characteristics of NVI.

1. Novelty (or innovativeness) refers to the degree to which the NVI differentiates from the previous norms in the industry and the marketplace. This feature of the NVI varies by actor and includes the efficiency improvements, and complementarities offered as a bundle in addition to the usual innovations in the marketplace.

2. Appropriability refers to the possibility of capturing the returns from the exploitation of an NVI and preventing others from doing so. In addition to the intellectual capital protection potential, this characteristic also reflects the revenue model; the value, rarity, imitability, and organisation (VRIO); and represents greater resource endowments towards the protection of novelty in the NVI. Appropriability also represents the key reference points to consider while evaluating whether to pursue entrepreneurial opportunities 
3. Diffusability refers to the intended market offering's potential for being rapidly adopted and socially communicated. This represents a composite score of the potential users' reaction on the relative advantage, compatibility, complexity, try-ability, and observability of the NVI.

4. Scalability refers to the size of the increments by which the NVI can be implemented and expanded and by the relative ease with which that minimum size can be multiplied, as well as any limits to the number of possible multiplications. It represents the minimum efficient scale with which an NVI can enter the market and is determined from the cost calculations depending on the production technologies that the NVI plans to use. From the point of view of the investors, this should include the variance in the estimated potential, and the unpredictable relationship between the scalability and the profit potential.

5. Scope refers to the breadth and depth of the operations and market offerings of the imagined new venture. This refers to the narrowness/broadness of the product/service offered as well as the range of the value chain it covers. A narrower scope of a new venture is associated with focused strategies and speed of successful establishment. On the other hand, a wider scope indicates the spreading of risks as a positive while complications in novelty and other NVI characteristics are negatives.

\section{The Kickstarter Website}

Referring to the research gap stated above, and to the operationalisation of the characteristics of the NVIs proposed by Davidsson and Tonelli (2013) and Davidsson (2015), the current study uses projects from the Kickstarter website to validate the role of five characteristics of the NVI construct towards the decision to invest. The following paragraphs summarise the main features of the Kickstarter website.

This website offers an online crowd-funding platform for entrepreneurs, investors, and supporters (backers) who directly and indirectly support the entrepreneurs in their venture investments without the involvement of large corporations. After the approval of a project by the Kickstarter admin team, specified amounts of donations are set as a target from individual donors. The funds can be collected only if the project reaches its fund-raising goal and Kickstarter charges $5 \%$ of the money raised as fees. The website offers 15 different product/service categories, and since its inception in 2009 to date, more than 5.8 million people have pledged over US\$1billion on more than 130,000 projects. 
The website provides every participating entrepreneur with a window (generally 30 days, or otherwise, as decided by the entrepreneur him/herself), to pitch and promote the project, and find backers and investors. The website displays projects in various categories, such as projects we love, projects trending, projects nearly funded, and projects just launched. The Kickstarter administration team screens the project applications and after the selection, a project is launched for investment. The investors are expected to back and/or invest in the project, with the percentage of investment achieved, the number of backers, and the remaining days/hours to go displayed on the website. Towards the end of the launch window, projects are classified into newest, oldest, popular, most funded, and most backed. As a crowdfunding website, Kickstarter has some market advantages over the usual financing and investment methods. These include increased consumer awareness through improved dissemination of product knowledge. From an entrepreneur's point of view, crowdfunding websites such as Kickstarter assist in establishing connections, gaining approval, maintaining control, and learning new skills.

The appropriateness of the Kickstarter website as the data source for this study on NVIs is justified due to several reasons. First, the concept of the NVI revolves around the "outlines of a future venture that give direction to action and creation of new economic activities" (Davidsson \& Tonnelli, 2013, p. 5). Similarly, the Kickstarter projects are ambitious, innovative, and imaginative ideas, which have a clear goal and deliver a product/service at the end. Second, the concept of the NVI includes innovative ideas and those that concern the introduction of a new competitor to the market context. Similarly, Kickstarter includes projects, which either represent a completely new idea or offer an added complementarity to an existing product/service. A third justification is that referring to the studies by Man and Lau (2000), and Boas, Dias and Amtmann (2014), every successful entrepreneur must have multiple competences and differentiated qualities. Among these are those, which are opportunity related, relationship related, conceptual, administrative, strategic, and behavioural. Boas et al. (2014) stated that among the opportunity related competences are access to information, identification of favourable scenarios, and evaluation of the appropriate conditions for business. Entrepreneurs assess opportunities through psychological and environmental factors and whereas opportunity recognition may happen at an individual stage, opportunity exploitation is collaborative (Shane, 2003). Crowd funders (such as Kickstarter) help coordinate efforts, exploit opportunities, and provide a virtual collaborative space, which is essential for the entrepreneurs (Kraut \& Resnick, 2011; Shane, 2003;). Principally, the crowdfunding websites also bear similarities with what Burg and Romme (2014) called the social embeddedness or social network, or what Klein (2008) referred to as the investment as a unit of analysis view. 
Entrepreneurial opportunities are defined as ideas for an innovation that may have value after further investment (Kornish \& Ulrich, 2011). However, the financing of an investment in opportunities is difficult because the information that entrepreneurs possess about the new ventures is usually restricted to themselves and not shared with the potential financiers (Barry, 1994; Gompers, 1995). Investors are faced with risky investment opportunities in which both the opportunities and the entrepreneurs may go wrong (Shane \& Cable, 2002). In such circumstances, investors rely on the characteristics of the venture ideas aside from the external factors and the entrepreneurship-opportunity nexus (Davidsson, 2015). Shane (2000) posited that the information about opportunities serves as the basis on which individuals become entrepreneurs. Klein (2008) referred to opportunities as "black box" (p. 183), and suggested that opportunities are those latent constructs that are manifested in entrepreneurial action. Klein also suggested replacing "projects" (originally proposed by Casson \& Wadeson, 2007) as representing opportunity exploitation rather than opportunity itself.

\section{The Current Study}

\section{Study variables}

The aim of the current study was to test the validity of the five NVI characteristics towards the decision to invest. To obtain a common consent and a generalised view, five experienced entrepreneur-investors were recruited as raters for this study. The decision to recruit five raters is based on the argument that the NVI construct represents the subjective perception of an entrepreneur. Hence, the use of more than one rater is thought to improve the consistency and reliability of the analysis as well as creating absolute agreement (Ritchie \& Spencer, 2002; Wynd, Schmidt, $\&$ Schaefer, 2003). Following the recommendations of Lynn (1986), the current study employed five raters. The average age of the five entrepreneur-investors was 35 years old and they also had an average of seven years of entrepreneurial experience. The entrepreneurial experience included a diversity of fields such as food and health, consumer durables, service industries, and information technology. These entrepreneur-investors made an average yearly investment of 30 million Thai baht and employed 30-50 people. It is noteworthy that the entrepreneurs were not informed of the data source or of the amount of finance or number of backers behind each project (as it unfolded on the website).

\section{Dependent variable 1 - The decision to invest or not}

Referring to these previous conceptualisations of the outcomes of opportunities, the current study assesses the dependent variable as a dichotomous variable 
representing the decision to invest or not. The scores of this dependent variable are derived from the judges as either a decision to invest (1) or a refusal to invest (0). The judges act as raters and assess each project on the five characteristics. In addition, the judges also rated the project on a categorical variable of worth investing or not worth investing.

\section{Dependent variable 2 - The number of backers from the Kickstarter website}

To ensure the validity of the findings from the first dependent variable, a parallel regression analysis was conducted with the "number of backers" as a dependent variable. The data on the number of backers were obtained from the Kickstarter website and organised into categories of "less than 1000", "1001 to 2000", "2001 to 3000 ", and the like. The findings from this regression analysis were used for making a comparison with that of the previous analysis and are discussed in the Results and Findings section.

\section{Independent variables}

The five NVI characteristics together represent a set of conceptually overlapping features of new venture ideas, which combine to determine the outcome of the entrepreneurial process. Previous studies have provided empirical support for the five characteristics. For instance, Davidsson, Hunter, and Klofsten (2006) suggested that originality (novelty) has a significant impact on the overall nature of the new venture. With respect to the venture creation process, Samuelsson and Davidsson (2009) stated that because emerging ventures are non-existent in their initial time, much of the research on the new ventures focuses on the characteristics of the entrepreneurs and not on the resources needed to start the emerging venture. Gruber (2004) suggested that, for new ventures, it is important to assess the subtle characteristics, such as innovation and diffusion. Eckhardt, Shane, and Delmar (2006), Zhao, Song, and Storm (2013), and Stampfl et al. (2013) all suggested that scalability entails a competitive price in the industry, and that "ventures with a high degree of scalability achieve better performance" (Zhao et al., 2013, p. 793). As a measure of new venture success, Mullins and Forlani (2005) suggested that investors assess the risk propensities and preferences for gauging the appropriateness. Shepherd (1999) and Zimmerman and Zeitz (2002) stated that scope was a significant consideration for a new venture success. Based on the theoretical support of Davidsson (2015) and of Davidsson and Tonelli (2013), as well as the empirical support from previous studies, the current study hypothesises that: 
H1: The more novelty a project has, the greater its chance of acquiring investment.

$\mathrm{H} 2$ : The more appropriately a project captures and protects the resource endowments towards novelty, the greater it's chance of acquiring investment.

H3: The more easily a project is adopted and socially communicated, the greater its chance of acquiring investment.

H4: The more scalable (expandable) a project is, the greater its chance of acquiring investment.

H5: The more correct the proportion of the scope of the project is with respect to other characteristics, the greater its chance of acquiring investment.

\section{THE METHOD}

The current study draws upon the concept of the NVI (Davidsson 2015; Davidsson \& Tonelli, 2013) and utilises secondary data from the Kickstarter website to determine the applicability of the characteristics in the NVIs. The objective of this study was to determine the applicability of the characteristics of the NVI and their significance towards the decision to invest. To detail the extent of the investment that the NVI received at the end, and as a follow-up to the study, data were collected from the website on two additional items: the number of people who backed the idea, and the percentage of investment that they would like to make. The number of backers was also used for a parallel analysis. Altogether, data were collected from 100 random NVIs. It is notable that the focus of the current study was the assessment of NVI characteristics, and hence, projects for all categories of products/services were considered suitable for the study sample.

The dependent variable of the decision to invest was graded as a binary variable with (0) decision not to invest, and (1) decision to invest. The independent variables of the NVI characteristics were graded on a 5-point Likert scale, ranging from " 1 = not at all" to " $5=$ extremely". Apart from the aforementioned characteristics of the NVI, Davidsson and Tonelli (2013) also proposed some actor (entrepreneur)dependent NVI characteristics. These included characteristics linked to the actor himself or to other actors in the social context, characteristics linked to the external environment, and characteristics linked to the process (e.g., the degree of completeness of the aspects of the project, and the amount of change). However, due to the nature of the sample for this study, these characteristics could not be included. More on this will be covered in the Limitations of the Study section. 


\section{RESULTS AND FINDINGS}

As previously mentioned, the data for the dependent variable of deciding whether to invest or not were obtained by using a Likert scale. The aim of this study was to indicate the effect of the NVI characteristics on the decision to invest. Therefore, the dependent variable was dichotomous, indicating " $0=$ decide to invest" and " 1 = decide not to invest". The projects with the "decide to invest" or "worth investing" classifications were analysed further, and those for which investment was denied were excluded from the analysis. Of the 100 recorded NVIs on the Kickstarter website, the raters (commonly) selected 80 for investment. This selection was based on the percentage of funding received for the projects. The excluded 20 project ideas had received zero percent funding at the time of the decision of exclusion. Keeping the objective of assessing the NVI characteristics for the project ideas, the remaining 80 ideas were considered for further analysis. Table 1 presents the correlation coefficients for the study variables for these 80 project ideas.

Pearson's correlation coefficient was computed for the study variables. The correlation analysis indicated that dependent variable 1 (decision to invest) was positively correlated with all the independent variables. Similarly, dependent variable 2 (number of backers) depicted medium correlations with all independent variables. Table 1 indicated that among the studied variables, none of the correlations was higher than 0.85 . This implies that this is not a sufficient condition to indicate a high degree of relationship among variables or multicollinearity (Schroeder, Lander, \& Levine-Silverman, 1990).

Table 1

Correlations among study variables

\begin{tabular}{llcccccccc}
\hline & & Mean & SD & 1 & 2 & 3 & 4 & 5 & 6 \\
\hline 1 & Novelty & 3.14 & 0.71 & - & & & & & \\
2 & Appropriability & 2.62 & 0.51 & $0.68^{* * *}$ & & & & & \\
3 & Diffusability & 2.97 & 0.54 & $0.72^{* * *}$ & $0.71^{* * *}$ & & & & \\
4 & Scalability & 2.95 & 0.59 & $0.62^{* * *}$ & $0.65^{* * *}$ & $0.75^{* * *}$ & & & \\
5 & Scope & 3.03 & 0.58 & $0.69^{* * *}$ & $0.60^{* * *}$ & $0.62^{* * *}$ & $0.73^{* * *}$ & & \\
Investment decision & & & & & & & & \\
6 & (DV1) & 0.45 & 0.50 & $0.69^{* * *}$ & $0.70^{* * *}$ & $0.71^{* * *}$ & $0.71^{* * *}$ & $0.67^{* * *}$ & \\
7 & Backers (DV2) & 2.49 & 1.90 & $0.27^{*}$ & $0.39^{* * *}$ & $0.33^{* *}$ & $0.25^{*}$ & $0.32^{* *}$ & $0.29^{* *}$ \\
\hline
\end{tabular}

Note: ${ }^{*} p<0.05$ level; ${ }^{* *} p<0.01$ level; ${ }^{* * *} p<0.001$ level; DV 1: dependent variable 1; DV 2: dependent variable 2 
A linear regression technique was chosen to analyse the relationship between the characteristics and the dependent variables (separate dependent variables for two parallel regression analyses). Table 2 summarises the findings from the two parallel analyses.

Table 2

Regression analysis results $(n=80)$

\begin{tabular}{|c|c|c|c|c|}
\hline \multirow{2}{*}{ IV } & \multicolumn{2}{|c|}{ DV = Investment decision by judges } & \multicolumn{2}{|c|}{$\mathrm{DV}=$ Number of backers } \\
\hline & $\beta$ & S.E. & $\beta$ & S.E. \\
\hline Novelty & 0.16 & 0.08 & -0.13 & 0.47 \\
\hline Appropriability & $0.23^{* *}$ & 0.10 & $0.33^{* *}$ & 0.60 \\
\hline Diffusability & 0.17 & 0.11 & 0.21 & 0.66 \\
\hline Scalability & 0.22 & 0.10 & -0.22 & 0.59 \\
\hline Scope & 0.14 & 0.10 & 0.24 & 0.56 \\
\hline $\mathrm{R}^{2}$ & $0.65^{* * *}$ & & $0.43^{* *}$ & \\
\hline F-value & $28.07(5,74)$ & & $3.44(5,74)$ & \\
\hline
\end{tabular}

Note: ${ }^{*} p<0.05 ;{ }^{* *} p<0.01 ;{ }^{* * *} p<0.001 ; \mathrm{IV}=$ independent variable; $\mathrm{DV}=$ dependent variable

The results of the regression analysis suggested that among the five characteristics of the NVI, appropriability - the variable representing the possibility of capturing returns from the NVI - was the only significant characteristic that affected the investment decision. The regression model for the dependent variable of the investment decision made by the panel of judges explained $65 \%$ of the variance. The independent variable of appropriability $(\beta=0.23, p<0.05)$ was significantly related to the decision to invest. Similarly, from the parallel analysis with the number of backers from the Kickstarter website as the dependent variable, the model explained $43 \%$ of the variance, and the independent variable of appropriability $(\beta=0.33, p<0.05)$ emerged as the sole indicator of investment decisions. These findings indicate support to the $\mathrm{H} 2$.

However, notably, none of the other variables significantly predicted the dependent variable indicating that none of the other hypotheses ( $\mathrm{H} 1, \mathrm{H} 3, \mathrm{H} 4$, and $\mathrm{H} 5)$ found support with the current data of project ideas.

\section{DISCUSSION}

The data from the Kickstarter website indicated support towards the NVI characteristic of appropriability. The findings of this study bear resemblance to those of previous studies on appropriability (e.g., Baker, Gedajlovic, \& Lubatkin, 
2005; Shane \& Venkataraman, 2000), and appropriability regimes (Schaltegger \& Wagner, 2011), which indicated that appropriability was a measure of the innovators' share of the value created by the innovation (Gans \& Stern, 2003). Subsequently, it is notable that none of the other NVI characteristics were significantly related to the outcome variables. However, the study poses some incongruence because unlike other studies (e.g., Corner \& Ho, 2010; Parker, 2011; Shane, 2001), none of the other four NVI characteristics were found to be significantly related to the investment decision. This discrepancy can be attributed to the absence of a set of questions directed towards an assessment of the NVI characteristics. Previous studies (e.g., Davisson, 2015) also stressed this limitation.

\section{CONCLUSION}

Although opportunities define the boundary and exchange conditions of entrepreneurship (Short et al., 2010), and, "to have entrepreneurship, you must first have opportunities" (Shane \& Venkataraman, 2000, p. 220), the characteristics of opportunities are a less explored area of the entrepreneurial process (Davidsson, 2015). Taking the concept of the entrepreneurship nexus (Shane \& Venkataraman, 2000) forward, the current study tested the five characteristics of NVIs (Davidsson, 2015; Davissson \& Tonelli, 2013) and their effect on the decision to invest or not. Using a sample of 80 projects from the Kickstarter website, the current study confirmed the significance of the appropriability of the NVI towards the decision to invest. The findings of this study will benefit future entrepreneurs in examining NVIs as antecedents to their decision of whether to pursue or invest. The findings of this study would be equally beneficial to those nascent entrepreneurs who are looking to start working on their first projects and wish to assess their NVIs in a way that leads to a higher degree of assurance in the outcomes of the entrepreneurial process. More studies aimed at confirming the construct validity of the characteristics of NVIs are desirable in the future.

\section{Limitations of the Study}

The current study aims to explore the five characteristics of new venture ideas to determine their influence on the decision of whether to invest in the NVI or not. This study proposed noteworthy findings in terms of establishing appropriability as a decisive factor in the investment decision. To the authors' knowledge, this study is the first one to explore the validity of the five NVI characteristics. Nevertheless, it should also be noted that this study also includes a few limitations. The first limitation is that this study did not cover a comprehensive list of characteristics as proposed by Davidsson and Tonelli (2013) and Davidsson (2015). As stated 
earlier, it is noteworthy that apart from the actor (entrepreneur)-independent NVI characteristics, Davidsson and Tonnelli (2013) also proposed key actor-dependent NVI characteristics, such as actor knowledge and skills and resource relatedness. However, these characteristics cannot be explored in the current study because of the nature of the data. As the current study uses secondary data, it is paramount that the data appropriately fits the research question and it is plausible that the availability or unavailability of such data limits the analysis in some way (Hox $\&$ Boeije, 2005). In addition, the characteristics related to the environment, such as market growth and barriers, could not be covered in this current study. The Kickstarter website catalogues the projects into 15 product/service categories. Hence, the website only offered what can be called an inward-looking perspective similar to the resource-based theory (Lavie, 2006). It is noteworthy that although these characteristics depict a significant relationship with the NVI construct, the characteristics act as moderators and depict an indirect effect not a direct one. Hence, these characteristics were not included.

Second, as the current study is essentially based on secondary data, it lacks direct contact with the entrepreneurs. Hence, characteristics such as the entrepreneur's knowledge and resources or the social context of the entrepreneur could not be identified. The other characteristics which were impossible to obtain were the completeness and the amount of change aspects of the entrepreneurial process. The process characteristics were also not included because no apparent evolution of the NVI could be observed during the process of data collection. Exclusion of these variables might have hindered a comprehensive analysis and resulted in insignificant findings (James \& McCulloch, 1990).

Thirdly, it is notable that the current study collected the data for 80 projects based on the concept of the NVI and its characteristics. However, there was no definitive scale for measuring NVI characteristics and the data were collected based solely on the definitions of the five characteristics proposed by Davidsson and Tonelli (2013) and Davidsson (2015). There is a possibility that the latent constructs representing the characteristics of the NVI (e.g., novelty, appropriability, diffusability, scalability, and scope) conceptually overlap each other and lack independent construct validity. The high correlation coefficients also support this hypothesis. Nevertheless, it is notable that the current study is among the first studies to focus on the application of the NVI construct and the characteristics of the NVI. It is plausible that the aforementioned characteristics lack a definite criterion measure (Cronbach \& Meehl, 1955) and construct validity. It is, therefore, advisable that future studies should focus on the development of a set of questions based on the definitions and, thereafter, test and verify the instrument used for the measurement of the five characteristics. 
Lastly, despite the fact that correlation among studied variables was not high, the findings are not generalisable and must be replicated again in future study.

\section{ACKNOWLEDGEMENTS}

The study was funded by Stamford International University (Internal Research Funding, grant no. 0009/2018). The authors would like to thank Stamford International University for the research grant provided.

\section{REFERENCES}

Alvarez, S.A., \& Barney, J.B. (2007a). Discovery and creation: Alternative theories of entrepreneurial action. Strategic Entrepreneurship Journal, 1(1-2), 11-26.

Alvarez, S.A., \& Barney, J.B. (2007b). The entrepreneurial theory of the firm. Journal of Management Studies, 44(7), 1057-1063.

Alvarez, S.A., \& Barney, J.B. (2013). Epistemology, opportunities, and entrepreneurship: Comments on Venkataraman et al. (2012) and Shane (2012). Academy of Management Review, 38(1), 154-157. https://doi.org/10.5465/amr.2012.0069

Baker, T., Gedajlovic, E., \& Lubatkin, M. (2005). A framework for comparing entrepreneurship processes across nations. Journal of International Business Studies, 36(5), 492-504. https://doi.org/10.1057/palgrave.jibs.8400153

Baron, R.A. (2006). Opportunity recognition as pattern recognition: How entrepreneurs "connect the dots" to identify new business opportunities. The Academy of Management Perspectives, 20(1), 104-119. https://doi.org/10.5465/ amp.2006.19873412

Barry, C.B. (1994). New directions in research on venture capital finance. Financial Management, 3-15.

Boas, A.A.V., Dias, T.R.F.V., \& Amtmann, R. (2014). A comparative study of entrepreneurial competencies of small business' owners in the upper peninsula of Michigan, USA and companies winning the top prize in Brazil. The Entrepreneurial Executive, 19, 47-66.

Burg, E., \& Romme, A.G.L. (2014). Creating the future together: Toward a framework for research synthesis in entrepreneurship. Entrepreneurship Theory and Practice, 38(2), 369-397. https://doi.org/10.1111/etap.12092

Casson, M., \& Wadeson, N. (2007). The discovery of opportunities: Extending the economic theory of the entrepreneur. Small Business Economics, 28(4), 285-300. https://doi.org/10.1007/s11187-006-9037-7

Corner, P.D., \& Ho, M. (2010). How opportunities develop in social entrepreneurship. Entrepreneurship Theory and Practice, 34(4), 635-659. https://doi.org/10.1111/ j.1540-6520.2010.00382.x

Cronbach, L.J., \& Meehl, P.E. (1955). Construct validity in psychological tests. Psychological Bulletin, 52(4), 281-302. https://doi.org/10.1037/h0040957 
Dahlqvist, J., \& Wiklund, J. (2012). Measuring the market newness of new ventures. Journal of Business Venturing, 27(2), 185-196. https://doi.org/10.1016/j. jbusvent.2010.12.001

Davidsson, P. (2015). Entrepreneurial opportunities and the entrepreneurship nexus: A re-conceptualization. Journal of Business Venturing, 30(5), 674-695. https://doi.org/10.1016/j.jbusvent.2015.01.002

Davidsson, P., Hunter, E., \& Klofsten, M. (2006). Institutional forces: The invisible hand that shapes venture ideas? International Small Business Journal, 24(2), 115-131. https://doi.org/10.1177/0266242606061834

Davidsson, P., Recker, J., \& von Briel, F. (2018). External enablement of new venture creation: A framework. Academy of Management Perspectives (In press). https://doi.org/10.5465/amp.2017.0163

Davidsson, P., \& Tonelli, M. (2013). Towards and operable entrepreneurship nexus: Conceptualizing venture ideas and their characteristics. Academy of Management Proceedings, 2013(1), 12071. https://doi.org/10.5465/ambpp.2013.12071abstract

Dimov, D. (2011). Grappling with the unbearable elusiveness of entrepreneurial opportunities. Entrepreneurship Theory and Practice, 35(1), 57-81. https://doi. org/10.1111/j.1540-6520.2010.00423.x

Eckhardt, J.T., \& Shane, S. (2010). An update to the individual-opportunity nexus. In Z.J. Acs, \& D.B. Audretsch (Eds.), Handbook of entrepreneurship research (pp. 4776). New York: Springer. https://doi.org/10.1007/978-1-4419-1191-9_3

Eckhardt, J.T., \& Shane, S.A. (2013). Response to the commentaries: The individualopportunity (IO) nexus integrates objective and subjective aspects of entrepreneurship. Academy of Management Review, 38(1), 160-163. https://doi. org/10.5465/amr.2012.0192

Eckhardt, J.T., Shane, S., \& Delmar, F. (2006). Multistage selection and the financing of new ventures. Management Science, 52(2), 220-232. https://doi.org/10.1287/ mnsc. 1050.0478

Gans, J.S., \& Stern, S. (2003). The product market and the market for "ideas": Commercialization strategies for technology entrepreneurs. Research Policy, 32(2), 333-350. https://doi.org/10.1016/s0048-7333(02)00103-8

Gartner, W.B. (1985). A conceptual framework for describing the phenomenon of new venture creation. Academy of Management Review, 10(4), 696-706. https://doi. org/10.5465/amr.1985.4279094

Gompers, P.A. (1995). Optimal investment, monitoring, and the staging of venture capital. The Journal of Finance, 50(5), 1461-1489. https://doi. org/10.1111/j.1540-6261.1995.tb05185.x

Gruber, M. (2004). Marketing in new ventures: Theory and empirical evidence. Schmalenbach Business Review, 56(2), 164-199. https://doi.org/10.1007/ bf03396691

Hox, J.J., \& Boeije, H.R. (2005). Data collection, primary versus secondary. In K. KempfLeonard (Ed.), Encyclopaedia of social measurement, vol. 1, (pp. 593-599). Netherlands: Elsevier. https://doi.org/10.1016/b0-12-369398-5/00041-4 
James, F.C., \& McCulloch, C.E. (1990). Multivariate analysis in ecology and systematics: Panacea or Pandora's box? Annual Review of Ecology and Systematics, 21(1), 129-166. https://doi.org/10.1146/annurev.es.21.110190.001021

Klein, P.G. (2008). Opportunity discovery, entrepreneurial action, and economic organization. Strategic Entrepreneurship Journal, 2(3), 175-190. https://doi. org/10.1002/sej.50

Kornish, L.J., \& Ulrich, K.T. (2011). Opportunity spaces in innovation: Empirical analysis of large samples of ideas. Management Science, 57(1), 107-128. https://doi. org/10.1287/mnsc. 1100.1247

Kraut, R.E., \& Resnick, P. (2011). Encouraging contribution to online communities. In R.E. Kraut, \& P. Resnick, Building successful online communities: Evidencebased social design (pp. 21-76). Cambridge, MA: The MIT Press. https://doi. org/10.7551/mitpress/8472.001.0001

Lavie, D. (2006). The competitive advantage of interconnected firms: An extension of the resource-based view. Academy of Management Review, 31(3), 638-658. https://doi.org/10.5465/amr.2006.21318922

Lynn, M.R. (1986). Determination and quantification of content validity. Nursing Research, 35(6), 382-386.

Man, T.W., \& Lau, T. (2000). Entrepreneurial competencies of SME owner/managers in the Hong Kong services sector: A qualitative analysis. Journal of Enterprising Culture, 8(03), 235-254. https://doi.org/10.1142/s0218495800000139

Mullins, J.W., \& Forlani, D. (2005). Missing the boat or sinking the boat: A study of new venture decision making. Journal of Business Venturing, 20(1), 47-69. https://doi.org/10.1016/j.jbusvent.2003.08.001

Parker, S.C. (2011). Intrapreneurship or entrepreneurship? Journal of Business Venturing, 26(1), 19-34.

Ramoglou, S., \& Tsang, E.W. (2016). A realist perspective of entrepreneurship: Opportunities as propensities. Academy of Management Review, 41(3), 410-434. https://doi.org/10.5465/amr.2014.0281

Ritchie, J., \& Spencer, L. (2002). Qualitative data analysis for applied policy research. The Qualitative Researcher's Companion, 573(2002), 305-329. https://doi. org/10.4135/9781412986274.n12

Samuelsson, M., \& Davidsson, P. (2009). Does venture opportunity variation matter? Investigating systematic process differences between innovative and imitative new ventures. Small Business Economics, 33(2), 229-255. https://doi.org/10.1007/ s11187-007-9093-7

Schaltegger, S., \& Wagner, M. (2011). Sustainable entrepreneurship and sustainability innovation: Categories and interactions. Business Strategy and the Environment, 20(4), 222-237. https://doi.org/10.1002/bse.682

Schroeder, M.A., Lander, J., \& Levine-Silverman, S. (1990). Diagnosing and dealing with multicollinearity. Western Journal of Nursing Research, 12(2), 175-187. https://doi.org/10.1177/019394599001200204

Shane, S. (2000). Prior knowledge and the discovery of entrepreneurial opportunities. Organization Science, 11(4), 448-469. https://doi.org/10.1287/ orsc.11.4.448.14602 
Shane, S. (2001). Technological opportunities and new firm creation. Management Science, 47(2), 205-220. https://doi.org/10.1287/mnsc.47.2.205.9837

Shane, S. (2012). Reflections on the 2010 AMR decade award: Delivering on the promise of entrepreneurship as a field of research. Academy of Management Review, 37(1), 10-20. https://doi.org/10.5465/amr.2011.0078

Shane, S., \& Cable, D. (2002). Network ties, reputation, and the financing of new ventures. Management Science, 48(3), 364-381. https://doi.org/10.1287/ mnsc.48.3.364.7731

Shane, S., \& Venkataraman, S. (2000). The promise of entrepreneurship as a field of research. Academy of Management Review, 25(1), 217-226. https://doi. org/10.5465/amr.2000.2791611

Shane, S.A. (2003). A general theory of entrepreneurship: The individual-opportunity nexus. Cheltenham, UK: Edward Elgar Publishing.

Shepherd, D.A. (1999). Venture capitalists' assessment of new venture survival. Management Science, 45(5), 621-632. https://doi.org/10.1287/mnsc.45.5.621

Short, J.C., Ketchen Jr., D.J., Shook, C.L., \& Ireland, R.D. (2010). The concept of "opportunity" in entrepreneurship research: Past accomplishments and future challenges. Journal of Management, 36(1), 40-65. https://doi. org $/ 10.1177 / 0149206309342746$

Stampfl, G., Prügl, R., \& Osterloh, V. (2013). An explorative model of business model scalability. International Journal of Product Development, 18(3-4), 226-248. https://doi.org/10.1504/ijpd.2013.055014

Stevenson, H.H., Roberts, M.J., \& Grousbeck, H.I. (1989). New business ventures and the entrepreneur. Homewood, IL: Irwin.

Vogel, P. (2017). From venture idea to venture opportunity. Entrepreneurship Theory and Practice, 41(6), 943-971. https://doi.org/10.1111/etap.12234

Williams, D.W., \& Wood, M.S. (2015). Rule-based reasoning for understanding opportunity evaluation. Academy of Management Perspectives, 29(2), 218-236. https://doi.org/10.5465/amp.2013.0017

Wynd, C.A., Schmidt, B., \& Schaefer, M.A. (2003). Two quantitative approaches for estimating content validity. Western Journal of Nursing Research, 25(5), 508518. https://doi.org/10.1177/0193945903252998

Zhao, Y.L., Song, M., \& Storm, G.L. (2013). Founding team capabilities and new venture performance: The mediating role of strategic positional advantages. Entrepreneurship Theory and Practice, 37(4), 789-814. https://doi.org/10.1111/ j.1540-6520.2012.00513.x

Zimmerman, M.A., \& Zeitz, G.J. (2002). Beyond survival: Achieving new venture growth by building legitimacy. Academy of Management Review, 27(3), 414-431. https://doi.org/10.5465/amr.2002.7389921 